Doutorando em estudos da linguagem (UFRGS), tradutor e professor efetivo de lingua inglesa
na UFRPE. Autor de Multicultural Perspectives: na UFRPE. Autor de Multicultural Perspectives:
Teaching American Classics in South America, Teaching American Classics in South America,
publicado no Indiana English de Terre Haute-IN, EUA.

\section{Uma fagulha de vida: discutindo tradução, adaptação e plágio a partir de Max e os felinos, de Moacyr Scliar e A sucessora, de Carolina Nabuco}

\section{A sparkle of life: discussing translation, adaptation and plagiarism based on Moacyr Scliar's Max and the Cats and Carolina Nabuco's The Successor}

Paulo Roberto de Souza Ramos ${ }^{1}$

Universidade Federal do Rio Grande do Sul, Programa de Pós-Graduação em Letras, Porto Alegre, RS, Brasil.

\section{RESUMO}

Este artigo visa discutir dois casos envolvendo um suposto plágio de obras escritas por autores brasileiros por parte de escritores de língua inglesa. As obras nacionais são o romance A Sucessora (1934), de Carolina Nabuco, e a novela Max e os Felinos (1981), de Moacyr Scliar. A primeira traz semelhanças com Rebecca (1938), de Daphne du Maurier e a segunda compartilha a premissa de um de seus capítulos com A Vida de Pi (2001), de Yann Martel. Primeiramente, apresenta-se um pequeno resumo dessas quatro obras para situar os leitores, no qual semelhanças e diferenças são discutidas. Na sequência, a fim de compreender se houve, de fato, violação de direitos autorais, há uma seção dedicada ao conceito de plágio. Após essa, uma outra apresenta o que se entende por adaptação e como essa se diferencia e se relaciona com tradução. Em linhas gerais, conclui-se que o uso original de uma ideia anterior não exime obviamente um autor de referir suas fontes, ainda mais quando se toma algo emprestado de uma obra e/ou um autor menos conhecido.

Palavras-chave: Plágio. Adaptação. Tradução. Autoria.

\section{ABSTRACT}

This article aims to discuss two cases of alleged plagiarism committed by English-language writers against Brazilian authors. The Brazilian works are the novel The Successor (1934), by Carolina Nabuco and the novella Max and the Cats (1981), by Moacyr Scliar. The plot of the former bears some resemblance with Rebecca (1938), written by Daphne du Maurier and the latter shares a premise with Life of Pi (2001), by Yann Martel. First, a summary of each work is presented in order to situate the reader and their similarities and differences are discussed. After that, in order to understand whether there are grounds for talking about copyright infringement, there is a section about the legal aspects of plagiarism. Then, there is a section presenting what is understood by adaptation and whether or not it relates to translation. The general conclusion is that the origina use of an idea, naturally, does not exempt an author from acknowledging their sources, even more so when the idea is taken on loan from a lesser known work and/or author.

Keywords: Plagiarism. Adaptation. Translation. Authorship. 


\section{Introdução}

proposta do presente artigo é usar dois casos de suposto plágio envolvendo obras de dois autores brasileiros traduzidas para o inglês para debater os limites - legais e éticos - de se copiar um texto e/ou as ideias contidas nele. Tanto o romance A Sucessora (1934), de Carolina Nabuco, quanto a novela Max e os Felinos (1981), de Moacyr Scliar, foram vertidos para a língua inglesa como forma de atingir um público leitor supranacional. O primeiro traz semelhanças com Rebecca (1938), de Daphne du Maurier e o segundo tem a premissa de um de seus capítulos utilizada em $A$ Vida de $P i^{1}$ (2001), de Yann Martel. Primeiramente, é apresentado um pequeno resumo dessas quatro obras literárias. Na sequência, há uma seção na qual se busca resumidamente apresentar o entendimento em sentido amplo e em sentido estrito do que seja plágio, com o propósito de ofertar subsídios para avaliar se houve, de fato, violação de direitos autorais no uso atribuído aos autores anglófonos dos textos traduzidos. Depois disso, aborda-se o conceito de adaptação e como esse gênero se relaciona, se diferencia e/ou se aproxima da tradução.

\section{A Sucessora e Rebecca}

A Sucessora (1934) é a história de Marina, moça oriunda de uma tradicional família de fazendeiros fluminenses que se apaixona pelo novo-rico Roberto Steen, um viúvo. A falecida esposa de Roberto, Alice, é referência constante no ambiente para onde a nova Sra. Steen se muda. Pessoas lembram-se de suas ações em vida e objetos pessoais impõem sua presença póstuma. Dentre eles, o mais marcante é o magnífico quadro com

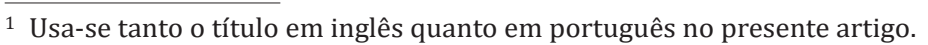

seu retrato que, assim como o de Dorian Gray, de Oscar Wilde, parece ter vontade própria aos olhos de Marina. A jovem protagonista é uma moça muito imaginativa e dada mais a experiências com o mundo literário do que com o real, o que talvez explique, em parte, a tempestade de sentimentos que o quadro de Alice lhe causa.

Apesar de conter uma história relativamente simples e sem surpresas, A Sucessora é um romance difícil de classificar em termos de gênero. Se, de fato, foi a "inspiração" para Daphne du Maurier escrever Rebecca (1938), seria de se esperar que contivesse um viés gótico e/ou de terror, como o romance da escritora britânica, mas o livro de Carolina Nabuco não resiste a uma busca mais estrita por tais elementos.

Quando as pessoas falam sobre ficção gótica, as características que mais frequentemente vêm à mente são o uso de cenários medievais (um castelo gótico ou abadia em ruínas), uma atmosfera obscura de horror e melancolia e incidentes misteriosos, macabros e violentos ${ }^{2}$ (RAMOS, 2001 p. 29, tradução nossa).

Na literatura gótica tradicional, a arquitetura e os cenários são usados metaforicamente na elaboração da trama e na construção da ambientação; através desses elementos, a entropia externa busca refletir a entropia interior. A metáfora da catedral gótica pode ser explorada a fim de mostrar como os medos na superfície da narrativa, instanciados por fantasmas, demônios, etc., remetem a fobias mais internalizadas, que se somam para inspirar terror no público leitor. Ramos (2002, p. 143, tradução nossa) explica o fenômeno nos seguintes termos: "o [conteúdo] gótico vai além do mundo visível percebido nas narrativas. Ele simboliza uma forma de

2 Do original: When people talk about gothic fiction, the characteristics that come most often to mind are the use of medieval settings (a ruined Gothic castle or abbey), a murky atmosphere of horror and gloom, and mysterious, macabre and violent incidents. 
amalgamação das ansiedades que flutuam [no mundo] livremente"3. Como veremos a seguir, o romance de Nabuco não explora semelhantes metáforas, nem faz uso de um aparato que possa ser classificado de gótico nos termos de Ramos (2001; 2002).

A Sucessora tem o clima angustiante da assombração representada pela figura de Alice. Tem a grande casa da Família Steen no Flamengo, que poderia ser comparada com as construções góticas das obras anglo-saxãs. No entanto, desde muito cedo o leitor é levado a concluir que o assombro que assola Marina é causado por uma imaginação fértil e uma suscetibilidade emocional por parte da protagonista. A Sucessora tem características realistas, mas sem as chamadas restrições impostas pelo gênero às ações das personagens. Também não segue à risca o que se poderia esperar de um romance romântico; em especial, na sua parte final e conclusão, traz muito de melodrama e marcas que gerações pós-televisivas relacionariam a novelas de TV. Nabuco tinha uma boa história nas mãos, mas resolve a trama com uma conclusão tradicional para o romance e recusa-se a vinculálo estritamente a gêneros ou escolas de maior prestígio na sua época. Um aspecto que transparece na obra é o que em inglês chama-se de local color. Além de enfocar muito o chamado nível psicológico de sua protagonista, Nabuco captura vividamente um Brasil pós-Abolição que tenta se tornar moderno e, para esse fim, a caracterização de suas personagens é bem trabalhada: desde os representantes do velho Brasil, como Dona Emília, mãe de Marina, e do seu primo e ex-noivo, Miguel, às personagens mais progressistas, como os membros do chamado "Grupo", como são designados os amigos de Roberto, marido de Marina, passando pelo retrato cheio de matizes da falecida Alice. O livro retrata os anseios e preconceitos de uma classe social brasileira que tem dinheiro e status para transitar entre seu país

3 Do original:Things Gothic go beyond the visible word perceived in the narratives. They stand for the amalgamation of free-floating anxieties. natal e a Europa. Ora vemos a protagonista reclamar da "caatinga" (NABUCO, [19--?], p.171) que vem dos negros em uma festa de rua, ora lemos em outra passagem o narrador onisciente vaticinar que "só depois de morto o velho Brasil, poderia o novo surgir, glorioso". (NABUCO, [19--?], p. 209). Dentro do romance, há também uma crítica explícita à "incipiente literatura brasileira” (NABUCO, [19--?], p. 215), no entanto, Nabuco não consegue escrever o novo romance brasileiro. Não consegue talvez porque não seja essa a sua proposta. A Sucessora traz traços cerebrais/psicologistas que remetem distantemente a um Poe do século anterior e que, se trabalhados, poderiam resultar em uma versão terra brasilis do tratamento da escritora estadunidense Joyce Carol Oates.

A própria Nabuco, que era versada em mais de um idioma, traduziu seu romance para o inglês com o propósito de lançá-lo no mercado exterior. Enviou uma dessas traduções para editores nos EUA, que não demonstraram interesse, e também para a Grã-Bretanha. Em relação ao envio feito para Londres, temos a primeira das coincidências envolvendo uma tradução e a produção de um original escrito em inglês. Alguns anos depois, o mesmo escritório lançaria o livro Rebecca, que viraria best-seller e teria os direitos comprados para uma versão cinematográfica lançada dois anos após a publicação do romance e que seria dirigida por Alfred Hitchcock, tendo como protagonistas os atores Laurence Olivier e Joan Fontaine. Assim como o livro, o filme teve bastante sucesso comercial. Fala-se que pouco antes do lançamento da película no Brasil, representantes da empresa de filmes teriam entrado em contato com Carolina Nabuco com o intuito de fazê-la firmar um termo declarando que as semelhanças entre seu livro e o romance de du Maurier, bem como o filme que foi feito a partir desse último, eram coincidências. Ela receberia uma compensação financeira por tal anuência. Nabuco se recusou a assinar qualquer tipo de declaração, mas também não pleiteou nenhum tipo de reparo pela via judicial. 


\section{Max, os Felinos e Pi}

Mais de sessenta anos depois do caso envolvendo A Sucessora e Rebecca, uma vez mais um autor popular de língua inglesa é acusado de usar indevidamente o conteúdo de uma obra elaborada por um brasileiro. Desta vez, o "acusado" é o canadense Yann Martel e o autor supostamente copiado, o gaúcho Moacyr Scliar. A premissa de Scliar para o segundo capítulo de sua novela, e que tem por título "O Jaguar no Escaler", é usada por Martel para escrever o romance Life of Pi (2001), vinte anos após a publicação do livro de Scliar. À medida que Life of Pi crescia em popularidade e, consequentemente, em rentabilidade, menos referências a sua origem brasileira eram feitas. Nas primeiras edições, Scliar recebera um lacônico agradecimento pela "fagulha de vida" ${ }^{4}$ que sua novela ofertara para a criação do romance do escritor norte-americano. Mais tarde, em especial nas edições feitas após a realização do filme baseado no livro, até mesmo a referência à "fagulha" foi omitida. A história de um jovem que, após o naufrágio do navio em que viajava rumo às Américas, é forçado a dividir um bote com um felino selvagem é a mesma tanto no capítulo de Max e os Felinos quanto no livro de Martel.

Brisolara (2013, tradução nossa), em texto sobre autoria, originalidade e plágio, escrito na esteira da polêmica envolvendo as semelhanças das histórias de Martel e Scliar, conclui seu trabalho afirmando que:

O que chocou o público foi ler um autor admitindo que tomou [algo] emprestado de outro escritor, como muitos o fazem. A afirmação de Martel de que era grato a Scliar levou muitos a pensar que ele [Martel] era um plagiador, como se plágio fosse o oposto de originalidade. Ficção é mais do que a oposição entre originalidade e plágio ${ }^{5}$.

\footnotetext{
A palavra em inglês é sparkle, que no dicionário on-line é definida como "uma pequena faísca ou partícula de fogo".

Do original: What shocked the public was to read an author admitting he had borrowed from another writer, as many do. Martel's statement that he was indebted to Scliar led many to think he was a plagiarist, as if plagiarism were the opposite of originality. There is more to fiction that the opposition between originality and plagiarism.
}

A afirmação ut supra deixa transparecer uma visão que busca se distanciar de um ideal mais romântico de autoria na direção de produções artísticas em um contexto pós-romântico e pós-moderno, no qual o uso criativo de textos e fontes novas e antigas se mesclam para a criação de uma nova obra, que não nega o que veio antes, mas o incorpora. Artisticamente, esse recurso é bem-sucedido - o sucesso de Martel é, em si, um testemunho de que a utilização que ele fez do material emprestado de Max e os Felinos foi exitosa. Entretanto, parece um tanto reducionista a afirmação de que as críticas têm origem no fato de o escritor estrangeiro ter reconhecido que tomou a ideia da obra de um outro autor. O fato é que as críticas em língua inglesa se baseavam na extrema semelhança da parte do enredo que descreve a personagem à deriva em um pequeno barco com um feroz felino. Além do mais, como já foi dito, as poucas palavras de referência à novela de Scliar desapareceram das subsequentes edições a que tivemos acesso. Mesmo que se concorde, até certo ponto, que todos usam "palavras repetidas", pois "quais são as palavras que nunca são ditas?"6, há que se distinguir entre citação de frases conhecidas de artistas populares e omissão consciente de informação que não é do conhecimento de grande parte do público.

A lei sobre direito autoral não considera como plágio a utilização de uma ideia alheia usada para a elaboração de uma obra escrita, seja ela ficcional (romance, conto, etc.) ou não ficcional (artigo, ensaio, etc.). A Sucessora inspirou em du Maurier uma história tecnicamente mais bem-acabada que a da autora brasileira. Life of Pi é uma grandiloquente história de aventura e superação com moldes bem distintos do proposto para o discreto Max. É inquestionável que Martel seja o autor do produto final chamado Life of Pi. Da mesma forma que na área da música popular, o cantor americano

${ }_{6}$ Trecho da letra da canção “Quase sem querer”, do grupo Legião Urbana, composta por Renato Russo. 
Eric Carmen é o criador da canção "All by myself" (1975) e os músicos ingleses Morrissey e Boz Boorer são os compositores de "The Teachers are Afraid of the Pupils" (1995). Os ouvintes que conhecem Rachmaninoff e Shostakovich ${ }^{7}$ provavelmente têm uma concepção sobre a autoria dessas canções distinta daquelas pessoas que não têm ciência de que partes das melodias das duas canções citadas foram retiradas de peças sinfônicas desses dois compositores eruditos. Se um dia as pessoas que conheceram primeiramente "All by Myself" e "The Teachers are Afraid of the Pupils" descobrirem que essas melodias preexistem às músicas cuja autoria atribuíam aos intérpretes populares, talvez se sintam ludibriadas com a omissão da informação e julguem que talvez houvesse razões escusas para não se creditar as fontes ${ }^{8}$.

\section{Plágio: entre o legal e o ético}

No mundo acadêmico e literário, plagiar poderia ser explicado como sendo o ato de usar as palavras escritas por outras pessoas como sendo de sua autoria. No Oxford Dictionaries On-line lemos para o verbete plagiarism, isto é, plágio, que se trata da "prática de pegar o trabalho ou as ideias de outra pessoa e passá-las como se fossem suas" (tradução nossa) ${ }^{9}$. O Oxford é o que denominamos de dicionário geral e suas definições ou, mais precisamente, suas paráfrases explanatórias visam a atingir um público

\footnotetext{
7 "All by myself" foi composta sobre o segundo movimento (Adagio sostenuto) do Piano Concerto No. 2 em dó menor, do compositor russo Sergei Rachmaninoff, enquanto que "The Teachers are Afraid of the Pupils" usa como melodia de base os compassos iniciais do 1o movimento da Sinfonia No. 5 em ré menor, do também russo Dmitri Shostakovich.

8 Eric Carmen, segundo Hoffman (2010, s.p) teve que citar Rachmaninoff nas edições posteriores ao lançamento da sua canç̃o em 1975. Já Morrissey não credita Shostakovich nas edições do álbum Southpaw Grammar (1995), disponíveis no Brasil.

Do original: The practice of taking someone else's work or ideas and passing them off as one's own. AGIARISM. In: ENGLISH Oxford Living Dictionaries. [Oxford: Oxford University Press, 2018]. Disponível em: https://en.oxforddictionaries.com/definition/plagiarism Acesso em: 10 set. 2018
}

não especializado. No entanto, se levássemos em consideração o que o verbete nos informa, usar a ideia de outra pessoa configuraria violação de propriedade intelectual em qualquer instância. O que ocorre, entretanto, é que tirando as marcas e patentes de produtos que são protegidos por lei, fazer uso simplesmente da ideia de um texto não configura, por si só, plágio. Para haver violação, é preciso usar as palavras escritas por um outro autor verbatim, sem os devidos créditos, como se quem as usou as tivesse escrito originalmente.

Um olhar passageiro pela história da literatura é suficiente para se verificar que copiar e usar um conteúdo ou um modelo anterior é uma constante em um número de períodos e escolas. Vieira (2002, p.107, tradução nossa) usa os argumentos de Haroldo de Campos em obra de 1981, que cita Goethe e Pound para justificar o uso criativo que um escritor pode fazer das obras de autores que o precederam:

Goethe é citado verbatim na defesa [de Campos] da acusação de plágio, com base em que só se pode produzir grandes obras ao se apropriar dos tesouros de outros; Pound também é citado em sua visão de que grandes poetas empilham/ajuntam tudo que conseguem tomar para si, emprestar ou roubar de seus antecessores e contemporâneos e acender sua própria luz no topo da montanha ${ }^{10}$.

Em agradecimento na primeira edição de Life of Pi (2001), Martel credita a Scliar a "fagulha de vida" que gerou seu romance. Consciente ou não da imagem conjurada por Pound sobre a luz que é acesa no topo da montanha, o fato é que o sucesso comercial de seu romance implica que a tal fagulha obtida do Max de Scliar deu origem a uma fogueira intensa, capaz de gerar a luminosidade de um poderoso farol.

${ }^{10}$ Do original: Goethe is quoted verbatim in his [Campos] defense of the accusation of plagiarism on Pound with the view that great pots pile up all the things they can claim, borsow or steal from also is forerunners and contemporaries and light their own light at the top of the mountain. 
Sobre as implicações de se publicar uma tradução de um texto em língua estrangeira protegido por direito autoral, Venuti (1995, p.185, tradução nossa) é didático e categórico ao dizer que: "Publicar sem autorização uma tradução de um texto em língua estrangeira protegido por direito autoral é pedir por um processo judicial, cujo custo irá exceder e muito os ganhos mesmo de uma tradução que venda bem"11.

O caso Scliar/Martel gerou artigos tanto jornalísticos quanto científicos. Entre os não acadêmicos, em uma perspectiva que ilustra o ponto de vista da comunidade de língua inglesa e que busca contemporizar de certo modo a situação conflitante, talvez por ter sido escrito anos após o início da celeuma, Simas $(2014$, p. 3) faz o seguinte resumo do acontecido:

O incidente todo se desenvolveu a partir de boato. Martel leu uma crítica de Max e os Felinos, mas não o livro em si e anos mais tarde foi inspirado pela sua percepção da versão da premissa do livro a escrever $A$ Vida de $P i$ que iria receber o Booker Prize. A imprensa brasileira fica sabendo dessa premiação, meio que lembra da novela de vinte anos atrás e, sem ler $P i$, grita "É plágio!"12 (SIMAS, 2014, p. 3, tradução nossa).

Parece ser fato que Martel não teve contato direto com o livro de Scliar, nem sob a forma direta de uma tradução para o inglês, e que o que lhe chamou a atenção foi, em linhas gerais, o argumento da novela. No entanto, um exame cronológico das declarações do escritor canadense deixa entrever que o autor de Life of Pi apresenta versões diferentes para o seu contato com a fagulha que deu vida ao seu romance. Todavia, a afirmação de que a

11 Do original: To publish an unauthorized translation of a copyrighted foreign text is to invite legal proceedings whose cost will far exceed the translator's income from even a bestselling invite legal pro

Do original: The entire incident evolved on hearsay. Martel read a review of Max and the Cats, but not the book itself, and several years later was inspired by his perceived version of the premise to write Life of $\mathrm{Pi}$, which went on to win the Booker Prize. The Brazilian press catches wind of this, half-remembers the twenty-year-old novella, and without reading Pi calls out, "Plagiarism!" imprensa brasileira, como um todo homogêneo, se baseou em hearsay (o que optei em traduzir como "boato") e que os autores das críticas não fizeram, como ele, a leitura direta e em sequência das duas obras para embasar suas afirmações é, no mínimo, leviana e não fica muito distante de presunção.

Com a visibilidade que Martel e seu romance obtiveram após a premiação do Man Booker Prize em 2002, jornais de várias partes do mundo, e em particular do mundo de língua inglesa, publicaram matérias tratando do fato relativo à semelhança entre as duas obras e insinuando, assim como os jornais brasileiros, que poderia se tratar de uma forma lato sensu de plágio $^{13}$. Na verdade, o que a imprensa em geral quis apontar é que houve o uso de uma ideia retirada de uma obra, sem que esta e seu autor recebessem os devidos créditos. Os créditos, que apareceram de maneira telegráfica e depois foram omitidos, não foram seguidos, nem de maneira informal, por meio de e-mail ou telefonema ${ }^{14}$.

De Boever ([2013]) cita uma grande passagem do ensaio que Martel escreveu e onde ele aborda a gênese de seu Pi. O texto é intitulado How I Wrote Life of Pi, e o que Simas (2014, p. 4, tradução nossa) disse ser uma forma de manipulação por parte da revista Veja para predispor os leitores contra Martel, nesse caso específico, não parece ser procedente, pois o próprio autor do ensaio torna explícita sua opinião sobre o uso inadequado da premissa da novela de Scliar: "Ah, as coisas maravilhosas que eu poderia fazer com essa premissa. Se eu tivesse pensado nisso, poderia ter algo grande com essa premissa. Mas - droga! - a ideia foi enviada por fax para outra musa ${ }^{15}$

Não se faz necessária uma análise semântica pesada para se notar

13 No mesmo ano da premiação do Man Booker Prize, i.e., 2002, foi publicado no The Guardian artigo escrito por Colin Blackstock falando sobre uma "confusão sobre plágio" envolvendo Martel

14 Essa expectativa frustrada de reconhecimento da importância da ideia foi registrada em comunicação pessoal do escritor ao autor deste trabalho.

15 Do original: Oh, the wondrous things I could do with this premise. [...] if only I had thought of it I could have done something great with it. But - damn! - the idea had been faxed to the wrong muse.] 
as cores minguadas com que o criador de $P i$ descreve o produto final de Scliar em contraste com "as coisas maravilhosas" e o "algo grande" que ele faria com a ideia que a musa entregou para o escritor gaúcho. A conclusão parece ser que os chamados boatos foram alimentados pelos comentários nada laudatórios feitos por Martel.

Davies ([2002]) faz referência às poucas palavras que Martel utilizou no seu agradecimento a Scliar. Poucas palavras que deram muito o que falar. $\mathrm{O}$ mesmo autor diz que a presidente do Man Booker Prize foi bastante enfática ao afirmar que não havia nenhuma semelhança entre os dois livros e que Martel teria "reconhecido livremente de onde a ideia se originou"16.

Apesar da negativa oficial feita pela organização que premiou Martel, a semelhança é ratificada por porta-vozes nas mídias digitais, como Johnson ([2002], tradução nossa), que, com tom irônico, diz que é preciso admitir que se trata de uma premissa bem incomum para um livro: "um garotinho sobrevive a um naufrágio e acaba dividindo um bote salva-vidas com um grande e feroz felino. Parece familiar?" 17.

Para que não pareça que apenas a imprensa brasileira saiu em defesa da grandeza e importância do Max, de Scliar, McConahay (2013) defende que Life of Pi é uma leitura de uma nota só em comparação com as várias camadas da trama em Max e os Felinos, a qual evoca emoções variadas.

Entre os diversos artigos sobre o livro de Martel e sua semelhança com a história de Scliar, há um publicado no jornal escocês The Scotsman que tem por título "The Claws are out” (As garras estão para fora). Além de tratar de questões já abordadas em outros textos, ele informa seus leitores sobre a

${ }^{16}$ Do original: Lisa Jardine, chairman of the Mann Booker Prize, was adamant that there was no similarity in the books. She thought Life of Pi was the best winner of the prize since Salman Rushdie's Midnight's Children. She added that Martel had freely acknowledged where the idea had originated.

${ }^{17}$ Do original: A little boy survives a shipwreck and winds up sharing a lifeboat with a large, predatory cat. Sound familiar? história do suposto plágio entre $A$ Sucessora $(1934)^{18}$, da carioca Carolina Nabuco, e Rebecca (1938), da inglesa Daphne du Maurier.

\section{Tradução e Adaptação}

Traduzir um texto envolve, em um grau maior ou menor, adaptar um texto. Poderia se questionar se há uma linha bem definida separando tradução de adaptação; ou se, ao termos um, necessariamente não temos o outro, em uma alusão ao conceito saussuriano de signo; ou se a separação entre um gênero e outro é algo gradiente: um texto tem mais características de tradução e menos de adaptação, por isso, opta-se em chamá-lo tradução e vice-versa. Em artigo online ${ }^{19}$ do blog Trusted Translations, o conceito de adaptação é apresentado como algo intrinsicamente ligado à tradução:

Uma das ferramentas usadas em tradução é a adaptação. É empregada em muitos casos, quando diferenças culturais entre diferentes falantes podem causar confusão que pode ser difícil de entender ou simplesmente nos impedir de entender um ao outro. Entretanto, adaptação não deve ser confundida com localização, que é usada quando o público alvo fala uma variedade diferente da mesma língua, como no caso da América Latina.

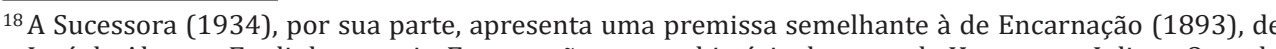
José de Alencar. Em linhas gerais, Encarnação conta a história do amor de Hermano e Julieta. Quando esta última morre, seu marido se torna um recluso e vive como se o espírito da sua falecida esposa estivesse com ele. Para criar uma espécie de triângulo, surge Amália, que se apaixona por Hermano e usa de seus atrativos para fazer com que ele se apaixone por ela e a tome em matrimônio. Hermano demonstra uma culpa mortal por gostar das duas mulheres. Seja uma manifestação de uma mente atormentada ou uma intervenção espiritual, quando o marido planeja se matar ateando fogo na cas onde moraram, o espírito de Julieta aparece e anuncia que Amália é, na verdade, sua encarnação. Isso faz com que Hermano mude de ideia e parta para o Velho Mundo com sua nova esposa. Quando retornam ao Brasil após alguns anos, eles trazem a filha do casal, que recebeu o nome de Julieta e que parece ser a síntese das duas mulheres de Hermano. Ironicamente, talvez em virtude de não haver uma tradução da obra para o inglês à época, ninguém levantou suspeiç̃̃o sobre as semelhanças do livro de tradução da obra para o inglês à época, ninguém leve gótico de Daphne du Maurier. ${ }^{19}$ Translation and Adaptation. Trusted Translations - Translation Blog. 12 ago. Disponível em: http:// translation-blog.trustedtranslations.com/translation-and-adaptation-2015-08-12.html. Acesso em: 7 dez 2017. 
Quando se adapta uma mensagem, não estamos traduzindo-a literalmente. Isso não significa, todavia, que quando se adapta uma mensagem ou ideia, não estamos sendo fiéis à mensagem original ou que não estamos fazendo bem o nosso trabalho (traduzir). Simplesmente, há situações em que é necessário adaptar ${ }^{20}$

O texto segue de maneira um tanto errática com elaborações e exemplificações da função da adaptação dentro do processo tradutório. Em certo momento, as adaptações são chamadas de "traduções livres". Se fosse um stub da Wikipédia, esse artigo estaria assinalado pela comunidade de especialistas como carecendo de fontes para apoiar as afirmações.

Saindo de um extremo que tenta com exemplos e conceitos imprecisos explicar o que é adaptação e indo para um outro extremo que reconhece e aceita a dificuldade ou impossibilidade de definir o termo, temos Whittlesey ([2012], p.xxx, tradução nossa) que diz que "grosso modo, há pouca ou nenhuma regra sobre o que constitui uma adaptação"21.

Nesse mesmo trabalho, encontramos um outro conceito que seria intermediário entre tradução e adaptação: a transposição.

Na transposição, há uma tentativa de produzir o original como o autor o teria feito se ele ou ela aparecesse no tempo e lugar sócio-históricos postos da transposição e mantivesse a consciência que criou cada sentença do original (WHITTLESEY, [2012], tradução nossa) ${ }^{22}$.

\footnotetext{
${ }^{20}$ Do original: One of the tools used in translation is adaptation. It is used in many cases, as cultural differences between different speakers can cause confusion that can sometimes be tricky to understand or simply prevent us from understanding each other. Adaptation is not to be confused with localization, however, which is used when the target audience speaks a different variant of the same language, such as in the case of Latin America. When adapting a message, we are not translating it literally. This does not mean, however, that when adapting a message or idea we are being unfaithful to the original message, or that we are not doing our job well (translating). Simply, there are situations in which it is message,
required.

${ }^{21}$ Do original: Generally speaking, there are few to no rules on what forms an adaptation.

22 Do original: In transposition there is an attempt to produce the original as the author might have done if he or she appeared in the given socio-historical time and place of the transposition and retain consciousness that created each sentence of the original.
}

Essa proposta parece remeter perigosamente à metáfora usada por Arrojo (1986) acerca do tradutor fictício Pierre Menard, do conto homônimo de Jorge Luís Borges e os limites da hipótese do “E se...". Com isso em mente, para a proposta deste texto, apenas os conceitos de tradução e adaptação são discutidos.

Baker e Saldanha (2009, p. 3, tradução nossa) explicam em termos abrangentes seu entendimento sobre adaptação, usando como recurso explanatório dizer que ela (adaptação) é o que a tradução não é, mas que a primeira é dependente da segunda:

Adaptação pode ser entendida como um conjunto de intervenções translativas que resultam em um texto que, em geral, não é aceito como uma tradução, mas que, no entanto, é reconhecido como representando um texto fonte. Como tal, o termo pode abarcar várias noções vagas, como apropriação, domesticação, imitação, reescritura, entre outras. Em sentido estrito, o conceito de adaptação demanda o reconhecimento da tradução como não-adaptação, uma forma, de certa maneira, mais restrita de transferência. Por essa razão, a história da adaptação é parasitária dos conceitos históricos de tradução ${ }^{23}$.

A conclusão a que chegam é de que adaptação é um termo que continua, mesmo nos dias de hoje, sendo uma metalinguagem um tanto quanto nebulosa usada por estudiosos da área de estudos de tradução.

Munday (2009, p.7, tradução nossa) diz que o que as tentativas contraditórias de definir o termo conseguem é dar destaque ao que chama de: "a dificuldade e, mesmo, a futilidade de se ter expectativa de categorias

${ }^{23}$ Do original: Adaptation may be understood as a set of translative interventions which result in a text that is not generally accepted as a translation but is nevertheless recognized as representing a source text. As such, the term may embrace numerous vague notions such as appropriation, domestication,

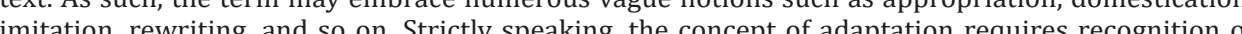

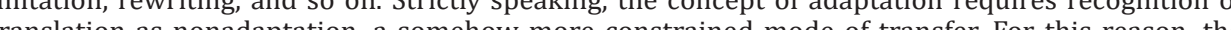
history of adaptation is parasitic on historical concepts of translation. 
invioláveis para o que seria melhor visto como um continuum de estratégias colocadas sob o termo guarda-chuva 'tradução'”24.

Valendo-se de referência a Platão, Wechsler (1998, p.47, tradução nossa) aborda adaptação e tradução afirmando que "não há um ideal platônico de adaptação; há [porém] um ideal platônico de tradução. E sempre que há ideais, há a impossibilidade de atingi-los. Qualquer coisa perfeita é impossível”25. Wechsler (1998, p. 81, tradução nossa) estabelece, posteriormente, distinção entre os termos tradução, versão e adaptação, usando, para isso, os critérios de forma e conteúdo:

Se o objetivo do intérprete é capturar a forma e o conteúdo tanto quanto for possível, então sinto que podemos chamar o resultado de tradução. Se o interesse do intérprete é somente por alguns aspectos do original - tais como suas imagens, à la Ezra Pound - então podemos chamar o resultado de versão. Poderíamos fazer a mesma coisa com um poema posto em prosa ou verso livre em uma outra língua: uma versão em prosa ou uma versão em verso livre. E se o intérprete está usando o original principalmente como inspiração, mas está efetivamente seguindo seus próprios rumos, então poderíamos chamar isso de uma adaptação ou, simplesmente dizer que ele está se baseando em algo. Robert Lowell chamava suas adaptações de imitações e essa palavra tem sido popular por séculos. Entretanto, imitação dá a impressão de algo mais próximo do que uma adaptação: quem imita tenta fazer a mesma coisa. Creio que a maioria dos leitores consideraria imitação apenas um outro nome para uma tradução, especialmente levando-se em consideração que raramente encontram o termo hoje em $\mathrm{dia}^{26}$.

\footnotetext{
${ }^{24}$ Do original: The difficulty, and even futility, of expecting watertight categories for what might better be viewed as a cline of strategies under the overarching term 'translation'.

${ }^{25}$ Do original: There is no Platonic ideal of an adaptation; there is a Platonic ideal of a translation. And wherever there are ideals, there is the impossibility of attaining them. The perfect anything is impossible.

${ }^{26}$ Do original: If the interpreter's goal is to capture the form and content as much as possible, then I feel we can call the result a translation. If the interpreter's interest is only in certain aspects of the original-such as its imagery, à la Ezra Pound - then we could call the result a version. We could do the same with a poem putinto another languge's prose or free verse: a prose version. We free-verse version. And if the interpreter is using the original primarily as an in: a prose vut eff on his own, then we could call it an apeptation or sinply say, based on. Robert Lowell called his
}

Keune e Vilmusenaho ([2011], tradução nossa) dão uma outra volta no confuso parafuso da relação entre plágio, adaptação e uso de uma ideia original:

Por regra, a Lei de Direito Autoral [Americana] proporciona ao autor o direito de usar a obra no original ou em forma modificada. Isso quer dizer que uma adaptação deve primeiro receber permissão do detentor dos direitos do original. Por exemplo, para se traduzir um romance é preciso obter permissão do autor da obra original. De acordo com a Lei de Direito Autoral, não é preciso permissão se a pessoa faz uso livre de uma obra para criar uma outra nova e independente. Essa condição está baseada na separação de uma ideia e sua expressão ${ }^{27}$.

No sistema jurídico britânico, encontramos convergência de avaliação no que diz respeito ao uso de ideias contidas em uma obra. A definição de propriedade intelectual já traz indicação da não aplicação de violação de direito autoral quando se tratar de uso de uma ideia:

Propriedade intelectual é algo único que você cria fisicamente. Uma ideia por si só não constitui propriedade intelectual. Por exemplo, uma ideia para um livro não conta, mas as palavras que você escreveu, $\operatorname{sim}^{28}$ (INTELIECTUAL...[201-?], grifos nossos).

adaptations imitations, and this word has been popular for centuries. However, imitation gives the impression of something closer than an adaptation: one who imitates tries to do the same thing. I think most readers would consider imitation just another name for a translation, especially since they rarely encounter the term today.

${ }^{27}$ Do original: As a rule, the Copyright Act provides the author with the exclusive right to dispose of the work in either the original or an altered form. This means that the author of an adaptation must first obtain permission from the copyright holder of the original work. For example, translating novel requires obtaining permission from the original work's author. According to the Copyright Act, permission from the copyright holder is not required if the person has drawn freely on a work Act, pere a new and in copent expression.
end intellectual property. For example, an idea for a book doesn't count, but the words you've written do. 
No Brasil, a lei que trata dos direitos autorais é a Lei no 9.610, de 1998. No texto explicativo sobre ela, lemos que o criador de toda obra intelectual deve receber recompensa se uma outra pessoa faz uso da sua produção. Além disso, somos informados de que

[...] a Lei no 9.610, de 1998, regula os direitos autorais, cuja gestão está a cargo da Diretoria de Direitos Intelectuais, do Ministério da Cultura (MinC). Obras e invenções que não sejam de caráter literário, artístico ou científico, como programas de computador, embora sejam protegidas pelos direitos autorais, estão sob responsabilidade do Ministério da Ciência e Tecnologia (MCT) e são reguladas pela Lei no 9.609, também de 1998 (ENTENDA..., 2009).

O que a lei sobre propriedade intelectual e direitos autorais nos países aqui arrolados diz é que há uma separação entre forma e conteúdo. Ideias fazem parte desse último e seu uso não viola, pelo que se depreende do que foi arrolado acima, direito algum.

\section{Considerações finais}

Do ponto de vista legal, não há como afirmar que os autores de Rebecca e Life of Pi plagiaram A Sucessora e Max e os Felinos, respectivamente. Nem se pode dizer que fizeram adaptações dessas obras, pois a relação entre os textos fonte e textos meta teriam que ser de outra natureza. Se excluirmos a hipótese da coincidência, o que pode ser dito é que as ideias para os romances em língua inglesa foram tiradas dos livros dos brasileiros a partir de traduções existentes nesse idioma. Tanto Geoffrey Chaucer ${ }^{29}$ quanto William Shakespeare ${ }^{30}$, para citar apenas dois renomados autores

\footnotetext{
${ }^{29}$ Chaucer (c.1342 -1400) foi um poeta e servidor público inglês, cuja obra mais conhecida são os Contos da Cantuária, escrito em inglês médio. Para mais sobre o autor, Cf. LUMIANSKY, 2018.

${ }^{30}$ Poeta, dramaturgo e ator inglês, batizado em 26 de abril de 1564 e falecido em 23 de abril de 1616. Para mais sobre William Shakespeare, Cf. SPENCER; BROWN; BEVINGTON, 2018.
}

em língua inglesa, fizeram amplo uso de histórias que eram conhecidas nas suas respectivas épocas a fim de tecer suas obras. Pode-se fazer duas observações sobre esse fato. A primeira é sobre o conceito de autoria. Mesmo para os dias de hoje, parece inquestionável que ambos os autores são os responsáveis pela criação dos trabalhos a eles creditados, mesmo que, para a elaboração dos mesmos, eles tenham usado ideias e premissas criadas por outros. A segunda é que, na atualidade, com o estabelecimento dos direitos autorais, espera-se que as pessoas citem as suas fontes, ainda mais quando se tratar de uma obra que não é amplamente conhecida na cultura alvo. Um Ariano Suassuna faz referências ao Bardo de Stratford-upon-Avon; são passagens e situações tidas como universais, a ponto de não necessitar maior explicitação. No entanto, se um autor brasileiro, com sua produção, naturalmente, em língua portuguesa, tivesse personagens ou enredos incorporados em obras produzidas em língua inglesa, um idioma que tem muito mais poder de circulação mundo afora, sem que isso fosse creditado, a situação seria outra. Em relação à utilização do manancial das ex-colônias pelos países do Velho Mundo e/ou países desenvolvidos e poderosos, como os EUA, isso parece perpetuar a tendência das metrópoles de se apropriarem das riquezas encontradas no Novo Mundo ${ }^{31}$. A direcionalidade do uso de ideias parece ser um aspecto importante: se é algo tirado de uma língua de menor status para uma de maior penetração global. Outro aspecto é se o inspirador e o inspirado estão em pé de igualdade, em particular, se ambos podem ser acessados pelo público alvo. A canção "Geni e o Zepelin", do musical A Ópera do Malandro (1978), de Chico Buarque, usa premissas retiradas da canção "Jenny dos Piratas"32, de Bertolt Brecht e Kurt Weill, e do conto "Bola de Sebo"33, de Guy de Maupassant; Chico cita o dístico

${ }^{31}$ Sobre questões pós-coloniais e como estas se aplicam em relação à literatura e à tradução. Cf. BAbSNETT; TRIVEDI, 1999.

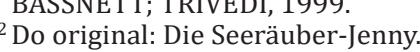

${ }^{33}$ Do original: Boule de Suif. 
final do soneto $116^{34}$, de Shakespeare, em “Tua Cantiga”, do álbum Caravanas (2017). No caso das obras aqui examinadas, a conclusão final parece ser que creditar não significa fazer uma citação segundo as normas da ABNT ou similar, mas reconhecer que sem a fagulha não haveria fogo, e sem ele, a fogueira em que foram feitos Rebecca e Life of Pi. Talvez a questão seja mais de cunho ético do que judicial. No entanto, como há muito dinheiro envolvido quando se trata de um best-seller internacional, o simples fato de se agir com ética poderia abrir brecha para questionamentos em outras instâncias.

Seja lá como se classifique a "fagulha de vida" que Max e os Felinos foi para a criação de Life of $P i$, há alguns fatos para os quais se tem evidência e que podem servir de insumo para que os leitores cheguem às suas próprias conclusões. O primeiro deles é que, no caso de Martel, o próprio autor concede ter gostado da ideia de base do capítulo da novela de Scliar, mas não do que o escritor gaúcho fez com ela; para ele, o bom uso é que gerou Life of Pi. O sucesso de vendas do romance pode servir como indicativo de que o público leitor em língua inglesa aprovou o produto literário construído com a premissa contida em Max e os Felinos. Outro fato é que dois artigos usados na elaboração deste texto, que estavam disponíveis na Internet (e estão salvos para consulta...), não aparecem mais mediante busca online ${ }^{35}$. Coincidentemente, eram artigos que tinham um teor bastante crítico contra Martel e seu romance. Talvez, as páginas que os hospedavam tenham deixado de existir. Ou pode-se aventar que, com a morte de Scliar em 2011, forças externas tenham ensejado eliminar os focos de polêmica sobre a origem do romance de Martel. Nessa perspectiva, não há razão de

\footnotetext{
${ }^{34} \mathrm{O}$ dístico no original em inglês é: “if this be error and upon me prov'd, / I never writ, nor no man ever lov'd".

35 Os textos em questão são McConahay (2013) e Simas (2014); a busca na Internet foi realizada em setembro de 2018.
}

se remexer na fogueira, pois a chama segue firme e forte, mesmo que o responsável pela faísca criativa que lhe deu origem não mais exista. Por fim, o entendimento neste artigo é de que não se trata de plágio a relação entre A Sucessora e Rebecca e entre Max e os Felinos e A Vida de Pi, uma vez que o que têm em comum são premissas (muito) parecidas e não a utilização de passagens textuais copiadas em tradução sem o devido crédito. Dito isso, se algum erro foi cometido, ele é de caráter mais ético do que legal, uma vez que os autores anglo-saxões não creditam de forma adequada as fontes de onde foram extraídas as ideias para seus livros; neste caso, como em outros semelhantes, as fontes eram obras menos conhecidas. Daphne du Maurier, na primeira metade do século XX, não contava com a Internet e tinha a seu favor o fato de a tradução de Carolina Nabuco não ter sido publicada comercialmente à época da redação e publicação de Rebecca. Martel, ao seu turno, não pode se valer desses álibis. No prefácio do autor [Author's note], texto de quatro páginas da versão digital do romance usada como referência para este artigo, Martel atribui a origem da sua história a uma viagem à Índia. $O$ crédito ao criador de $O$ Centauro no Jardim (1980) é feito de maneira bastante breve, por meio da já citada metáfora da "fagulha de vida ${ }^{36 ", ~ q u a s e ~}$ ao final do último parágrafo do relato. A posição em que a informação é oferecida no relato, somada à construção sintática enxuta, quase como um aposto, deixa pouco para se imaginar sobre a importância que quem o escreveu deseja atribuir à declaração. Mesmo que, na sua avaliação, Scliar tenha feito mau uso de uma boa ideia, há um débito a Max e os Felinos na gênese de Life of Pi.

${ }^{36} \mathrm{~A}$ passagem integral é: "quanto à fagulha de vida, eu a devo ao Sr. Moacyr Scliar [As for the spark of life, I owe it to Mr. Moacyr Scliar (p. 5).] 


\section{Referências}

ALENCAR, José de. Encarnação. São Paulo: Edições Melhoramentos, [19--?].

ARROJO, Rosemary. Oficina de tradução: a teoria na prática. São Paulo: Ática, 1986.

BAKER, Mona; SALDANHA, Gabriela. The Routledge Encyclopedia of Translation Studies. $2^{\text {nd }}$ ed. New York: Routledge, 2009.

BASSNETT, Susan; TRIVEDI, Harish. Post-Colonial Translation. New York: Routledge, 1999.

BLACKSTOCK, Collin. Booker winner in plagiarism row. The Guardian, London, 08 nov. 2002. Disponível em: https://www.theguardian.com/world/2002/nov/08/ bookerprize2002.awardsandprizes Acesso em: 28 out. 2017.

BRISOLARA, Valéria. The more you look, the less you see: Moacyr Scliar's Max and the Cats and Yann Martel's Life of Pi. Revista Línguas \& Letras, Cascavel, PR, v. 14, n. 27, segundo semestre 2013

DAVIES, Hugh. $£ 50,000$ Booker winner «stole idea from Brazilian author». The Telegraph, London, 09 nov. 2002. Disponível em: http://www.telegraph.co.uk/news/ worldnews/europe/spain/1412682/50000-Booker-winner-stole-idea-from-Brazilianauthor.html. Acesso em: 28 out. 2017.

DE BOEVER, Arne. Allegories of an Emergency: Yann Martel's 'Life of Pi'. Los Angeles Review of Books. Los Angeles, 24 apr. 2013. Disponível em: https://lareviewofbooks. org/article/allegories-in-an-emergency-yann-martels-life-of-pi/\#. Acesso em: 28 out 2017.

ENCARNAÇÃO (Romance). In: WIKIPÉDIA: a enciclopédia livre. [San Francisco, CA: Wikimedia Foundation, 2018]. Disponível em: https://pt.wikipedia.org/wiki/ Encarna\%C3\%A7\%C3\%A3o_(livro). Acesso em: 09 dez. 2017.

ENTENDA a lei de direitos autorais. In: GOVERNO do Brasil, Lei 9.610, de 1998, publicado: 05 nov. 2009. Disponível em: http://www.brasil.gov.br/cultura/2009/11/ entenda-a-lei-de-direitos-autorais. Acesso em: 08 dez. 2017. https://doi.org/10.26668/ indexlawjournals/2526-0014/2015.v1i1.111
HOFFMAN, Steve. Pop songs that borrow melodies from classical music or old, public domain songs. Steve Hoffman Music Forums, 23 mai. 2010. Disponível em: http:// forums.stevehoffman.tv/threads/pop-songs-that-borrow-melodies-from-classicalmusic-or-old-public-domain-songs.217152/ Acesso em: 12 set. 2018. https://doi. org/10.7591/9780801454813-010

INTELLECTUAL property and your work. In: GOV.UK. [Government Digital Service] Disponível em: https://www.gov.uk/intellectual-property-an-overview. Acesso em: 08 dez. 2017.

JOHNSON, Dennis Loy. Yann Martel gets an idea. Mobylives. 10 nov. 2002. Disponível em: http://www.mobylives.com/Yann_Martel.html. Acesso em: 28 out. 2017.

KEUNE, Anna; VILMUSENAHO, Sanna. Free Adaptation. 11 abr. 2011. Disponível em: https://wiki.aalto.fi/display/copyright/4.2+Free+Adaptation Acesso em: 05 dez. 2017.

LUMIANSKY, R. M. Geoffrey Chaucer. In: ENCYCLOPAEDIA Britannica. [Chicago, IL: Britannica Group, 21 out. 2018]. Disponível em: https://www.britannica.com/ biography/Geoffrey-Chaucer Acesso em: 15 nov. 2018. https://doi.org/10.1093/ odnb/9780192683120.013.5191

McCONAHAY, Mary Jo. The Life of Max -- Thoughts on Pi's Brazilian Creator. New America Media. 21 fev. 2013.

Disponível em: http://newamericamedia.org/2013/02/the-life-of-max----thoughts-onpis-brazilian-creator.php. Acesso em: 28 out. 2017.

MUNDAY, Jeremy. Issues in Translation Studies. In: MUNDAY, Jeremy. (ed.). The Routledge Companion to Translation Studies. New York: Routledge, 2009. https://doi.org/10.1080/07374836.2010.10524153

NABUCO, Carolina. A Sucessora. Rio de Janeiro: Ediouro, [19--?].

PLAGIARISM. In: ENGLISH Oxford Living Dictionaries. [Oxford: Oxford University Press, 2018]. Disponível em: https://en.oxforddictionaries.com/definition/plagiarism Acesso em: 10 set. 2018.

RAMOS, Paulo Roberto. The Gothic: Past, Present and Glimpses of the Future. Cadernos La Salle Letras, Canoas-RS, v. 1, n.9, p. 127-144, dez. 2002. 
RAMOS, Paulo Roberto. The New Gothic in Clive Barker's Books of Blood. 2001. $138 \mathrm{f}$. Dissertação (Mestrado em Letras) - Universidade Federal do Rio Grande do Sul, Porto Alegre, 2001. https://doi.org/10.29289/259453942018v28s1059

RUSSO, Renato. Quase sem querer. In: LEGIÃO URBANA, Dois. São Paulo: EMI, 1986.

SCLIAR, Moacyr. Max e os Felinos. Porto Alegre: L\&PM, 1981; 2013.

SHAKESPEARE, William. Sonnet 116. In: POETRY Foundation. [Chicago, IL, 20--?] Disponível em: https://www.poetryfoundation.org/poems/45106/sonnet-116-let-menot-to-the-marriage-of-true-minds. Acesso em: 10 set. 2018

SIMAS, Shed. On Life of Pi, Plagiarism and the Media. Página Pessoal. Postado em: 12 jul. 2014. Disponível em: http://www.shedsimas.com/on-life-of-pi-plagiarism-andmedia/. Acesso em: 28 out. 2017.

SPARKLE (Definição). In: DICTIONARY.com. [S.l., 20--?]. Disponível em: http://www. dictionary.com/browse/sparkle. Acesso em: 08 dez. 2017.

SPENCER, T.; BROWN, J.; BEVINGTON, D. William Shakespeare. In: ENCYCLOPAEDIA Britannica. [Chicago, IL: Britannica Group, 20 out. 2018]. Disponível em: https://www. britannica.com/contributor/Terence-John-Bew-Spencer/2817. Acesso em: 15 nov. 2018. https://doi.org/10.1108/09504120510613003

THE CLAWS are out. The Scotsman, 07 nov. 2002. Disponível em: https://www. scotsman.com/lifestyle/culture/books/the-claws-are-out-1-628107 Acesso em: 28 out. 2017.

THE COPYRIGHT Act of 1976. Wikipedia -The Free Encyclopedia. Disponível em https://en.wikipedia.org/wiki/Copyright_Act_of_1976 Acesso em: 08 dez. 2017.

TRANSLATION and Adaptation. Trusted Translations - Translation Blog. 12 ago Disponível em: http://translation-blog.trustedtranslations.com/translation-andadaptation-2015-08-12.html Acesso em: 07 dez. 2017.

VENUTI, Lawrence. The Translator's Invisibility: A History of Translation. New York: Routledge, 1995.
VIEIRA, Else Ribeiro Pires. Liberating Calibans: Readings of Antropofagia and Haroldo de Campos' poetics of transcreation. In: BASSNETT, Susan; TRIVEDI, Harish (ed.) Post-Colonial Translation: Theory and Practice. New York: Routledge, 2002. p. 96-113.

WECHSLER, Robert. Performing Without a Stage: The Art of Literary Translation. North Haven: Catbird Press, 1998.

WHITTLESEY, Henry. A Typology of Derivatives: Translation, Transposition, Adaptation. TranslationDirectory.com, junho de 2012. Disponível em: http://www. translationdirectory.com/articles/article2374.php. Acesso em: 05 dez. 2017.

Recebido em: 15/9/2018.

Aprovado em: $16 / 1 / 2019$

Publicado em: 20/6/2019; 